\title{
BMJ Open Consumption of fruits and vegetables and associations with risk factors for non-communicable diseases in the Yangon region of Myanmar: a cross- sectional study
}

Marte Kjøllesdal, ${ }^{1}$ Aung Soe Htet, ${ }^{1}$ Hein Stigum, ${ }^{1} \mathrm{Ne}$ Yi Hla, ${ }^{2}$ Hlaing Hlaing Hlaing, ${ }^{3}$ Ei Kay Khaine, ${ }^{3}$ Win Khaing, ${ }^{4}$ Aung Kyaw Khant, ${ }^{5}$ Naw Ohn Khin Khin, ${ }^{6}$ Kay Khine Aye Mauk, ${ }^{7}$ Ei Ei Moe, ${ }^{8}$ Hla Moe, ${ }^{3}$ Kyawt Kyawt Mon, ${ }^{4}$ Kyaw Swa Mya, ${ }^{9}$ Chomar Kaung Myint, ${ }^{10}$ Cho Yi Myint, ${ }^{11}$ Maung Maung Myint, ${ }^{12}$ Ohnmar Myint, ${ }^{13}$ Aye Aye New, ${ }^{8}$ Ei Sanda Oo, ${ }^{10}$ Khin Sandar Oo, ${ }^{3}$ Zin Zin Pyone, ${ }^{14}$ Yin Yin Soe, ${ }^{15}$ Myint Myint Wai, ${ }^{16}$ Nilar Win, ${ }^{4}$ Espen Bjertness ${ }^{1}$

To cite: Kjøllesdal M, Htet AS, Stigum H, et al. Consumption of fruits and vegetables and associations with risk factors for noncommunicable diseases in the Yangon region of Myanmar: a cross-sectional study. BMJ Open 2016;6: e011649. doi:10.1136/ bmjopen-2016-011649

- Prepublication history and additional material is available. To view please visit the journal (http://dx.doi.org/ 10.1136/bmjopen-2016011649).

Received 23 February 2016 Revised 28 June 2016 Accepted 6 July 2016

CrossMark

For numbered affiliations see end of article.

Correspondence to Dr Marte Kjøllesdal; m.k.kjollesdal@medisin.uio.no

\section{ABSTRACT}

Objectives: To explore the intake of fruits and vegetables in the Yangon region, Myanmar, and to describe associations between intake of fruits and vegetables (FV) and established risk factors for non-communicable diseases.

Design: 2 cross-sectional studies, using the STEPS methodology.

Setting: Urban and rural areas of the Yangon region of Myanmar.

Participants: 1486 , men and women, $25-74$ years, were recruited through a multistage cluster sampling method. Institutionalised people, military personnel, Buddhist monks and nuns were not invited. Physically and mentally ill people were excluded.

Results: Mean intake of fruit was 0.8 (SE 0.1) and 0.6 $(0.0)$ servings/day and of vegetables $2.2(0.1)$ and 1.2 (0.1) servings/day, in urban and rural areas, respectively. Adjusted for included confounders (age, sex, location, income, education, smoking and low physical activity), men and women eating $\geq 2$ servings of fruits and vegetables/day had lower odds than others of hypertriglyceridaemia (OR $0.72(95 \% \mathrm{Cl} 0.56$ to 0.94$))$. On average, women eating at least 2 servings of fruits and vegetables per day had cholesterol levels $0.28 \mathrm{mmol} / \mathrm{L}$ lower than the levels of other women. When only adjusted for sex and age, men eating at least 2 servings of fruits and vegetables per day had cholesterol levels $0.27 \mathrm{mmol} / \mathrm{L}$ higher than other men.

Conclusions: A high intake of FV was associated with lower odds of hypertriglyceridaemia among men and women. It was also associated with cholesterol levels, negatively among women and positively among men.

\section{INTRODUCTION}

Dietary factors contribute to a large share of the global burden of disease. Lim et $a l^{1}$

\section{Strengths and limitations of this study}

- Our study had a high response rate.

- Research was carried out in a population in which knowledge about risk factors for noncommunicable diseases is scarce.

- The questions on fruit and vegetable consumption were brief, including few details which could have enhanced the interpretation.

- Data collection was confined to one area of the country, thus making it difficult to make nationwide implications.

estimate that in $2010,10 \%$ of all deaths $(12.5$ million) were attributable to such risk factors. The number of deaths attributed to a diet low in fruits and vegetables (FV) alone was $\sim 6.6$ million. ${ }^{1}$ The protective effects of $\mathrm{FV}$ in the diet may be because of their high content of vitamins and minerals, as well as fibre, acting through mechanisms such as lowering blood pressure (BP), reducing antioxidant stress, improving lipoprotein profile and increasing insulin sensitivity. ${ }^{2}$

The WHO has recommended a daily intake of $\geq 5$ portions $(400 \mathrm{~g})$ of $\mathrm{FV}^{3}$ However, many people have lower intakes, both in high-income and low-income countries. ${ }^{4}$ A study from 52 low-income and middle-income countries reported low intakes of FV, defined as $<400 \mathrm{~g} /$ day, which varied from $37 \%$ among men in Ghana to $99 \%$ for women and men in Pakistan. ${ }^{5}$ In many Southeast Asian countries, large proportions of the population had a low intake. ${ }^{5}$ In Myanmar, the proportions were $83 \%$ 
among men and $85 \%$ among women. ${ }^{5}$ A low intake of $\mathrm{FV}$ was more common with increasing age and in lower income groups in many countries, and with rural settlement in some. ${ }^{5}$

A low intake of FV is associated with noncommunicable diseases (NCDs), such as cardiovascular diseases (CVDs), cancer and diabetes, ${ }^{13}$ as well as with its risk factors. ${ }^{3} 67$ Most studies are conducted in Western countries, and little is known about the association between the intake of FV and NCD risk factors in developing countries. ${ }^{8}$

Ischaemic heart disease and stroke are now the two leading causes of death in Southeast Asia, with $22 \%$ of all deaths attributable to them, which leads to $10 \%$ of the disability-adjusted life years (DALYs).$^{9}$ Diabetes is the eighth leading cause of death in this region. ${ }^{9}$ The high prevalence of, and mortality from these diseases, makes prevention an urgent task. Estimations of the occurrence of risk factors, and of associations between distal and more proximal factors, could help in directing the efforts of NCD prevention in a country. Based on previous studies, increasing the intake of FV could potentially be a means to reduce the risk of NCDs. Nonetheless, more knowledge is warranted on the association between the intake of FV and NCDs in this region, and about the differences in intake of $\mathrm{FV}$ in various sociodemographic groups.

Therefore, we first aim to explore the intake of FV and its relation with sociodemographic factors, and second, to describe associations between the intake of FV and established risk factors for NCDs; BP, body mass index (BMI), waist hip ratio (WHR), lipid profiles and blood glucose among women and men aged 25-74 years in the Yangon region of Myanmar.

\section{METHODS}

Two regional, cross-sectional studies focusing on the risk factors for NCDs were conducted in urban and rural areas of Yangon, Myanmar from September to November 2013 and September to November 2014, respectively. The studies followed the WHO STEPs-wise approach for the surveillance of risk factors for chronic disease. $^{10}$ The approach consists of three STEPs: (1) questionnaire survey based on sociodemographic characteristics, lifestyle-related habits and history of hypertension and diabetes; (2) Physical measurements including BP, body height, weight, waist and hip circumference; and (3) laboratory investigation for fasting lipid profiles (total cholesterol (TC), triglycerides (TG)) and fasting blood glucose (FBG) from venous blood sample.

\section{Sampling}

Men and women aged 25-74 years were included in the study. Institutionalised people, military personnel, Buddhist monks and nuns were not invited to the study. People who were physically and mentally ill were excluded. Based on the WHO sample size calculator for the STEP survey, ${ }^{10}$ we estimated that with a level of confidence of 1.96, a margin of error of 0.05 , a design effect of 1.5 and an expected response rate of $80 \%$, that we would need a sample size of 500 in each of the two studies for many of the risk factors, which has a prevalence of around $10 \%$, for example, hypertension and low levels of physical activity, or alternatively around $90 \%$, like a low intake of $\mathrm{FV}^{11}$ Other risk factors would require a sample size of $\sim 1000$, with a prevalence of around $20-25 \%$, for example, smoking and overweight. ${ }^{11}$ Based on these numbers and practical limitations, we considered a sample of 800 to be sufficient in each survey. Calculations were separately carried out for the urban and rural survey, with the aim to be able to compare men and women (number of sex/age estimates $=2$ ).

A multistage cluster sampling method was performed. First, six urban townships and six rural townships were randomly selected. Second, these townships were divided into clusters, villages in the rural townships and wards (urban unit of township) in the urban townships. Five villages from each of the six rural townships and five wards from each of the six urban townships were randomly selected (60 clusters altogether). Finally, 2627 households were randomly chosen within each cluster. Eligible household members were listed from selected households, and one was randomly invited to participate in the study. A male participant was selected from half the households and a female participant from the other half, and it was decided in advance which households should include a male and which should include a female. Data were collected during the daytime the first day, and then in the morning of the next day (blood samples). If a participant was not at home, she/he was contacted and an appointment was made for the next day if she/he was willing to participate, most often right after blood samples were taken. As a result, we had 1608 invitees with an equal gender distribution (804 from urban and 804 from rural areas). A total of $755(94 \%)$ from urban areas and of 731 (91\%) from rural areas completed STEPs 1 and 2. A total of $692(86 \%)$ participants from urban and 676 (83\%) participants from rural areas completed all three STEPs. The reasons given for not participating in STEPs 1 and 2 were 'not willing' and 'not having time'. In STEP 3, non-response was due to worries about blood tests. We excluded 13 pregnant women (3 from urban and 10 from rural areas), as maternal physiological changes in pregnancy might affect some of the risk factors assessed.

\section{Data collection and measurements}

Trained medical doctors interviewed the participants on sociodemographics and risk factors, and anthropometric measurements (body height, weight, waist and hip circumference) were taken using the WHO standard technique. ${ }^{10}$ For the urban study in 2013, four research assistants were recruited through the Myanmar Medical 
Association. A 2-day training and pretest were conducted in the Myanmar Medical Association with technical input from the Department of Medical Research (Lower Myanmar). The trainees were exposed to the methods of sampling and interpersonal communication, obtaining informed consent and a survey questionnaire on the first day. The second day of training was focused on interactive sessions to introduce data collection methods and correct measuring methods for all the STEPs. Anthropometric measures, physiological measurements and laboratory tests were practiced and trained according to the standardised method of the WHO guidelines. The standardisation of the instruments used in the fieldwork was carried out both before and during the training. The trained field researchers conducted a pretest comprising STEPs 1 and 2 of the survey in the Yangon region. Questionnaires were further clarified after the pretest, and the trained field researchers underwent a trial in practical skills after the clarification. The rural study in 2014 had the same principal investigator and person responsible for the training as in the urban study. Four new research assistants were recruited, using the same methods as in the urban study, and we used identical methods of training.

A measuring tape was used to measure individual's height without foot wear and any head gear, (measured to the nearest to $0.1 \mathrm{~cm}$ ). Body weight was measured with a portable electronic weighing scale to the nearest $0.1 \mathrm{~kg}$, and the participants were requested to wear light clothes without footwear during weighing. Waist and hip circumference measurements were conducted in a private place with the measuring tape. Waist circumference was taken at the midpoint between the lower margin of the last palpable rib and the top of the iliac crest (hip bone), in the standing position directly over the skin, according to the WHO STEP survey guidelines. The hip circumference was horizontally taken at the maximum circumference over buttocks, with both measured to the nearest $0.1 \mathrm{~cm}$.

Fifteen minutes after a face-to-face interview, BP was measured three times with a $3 \mathrm{~min}$ pause, using an OMRON M6 automatic BP monitor. Mean BP was calculated from the average of the second and third measurements. Venous blood samples were collected in a lipid tube and glucose tube containing fluoride and transported in cold boxes to the National Health Laboratory, Yangon, a reference laboratory of the Ministry of Health, Myanmar, by boat and/or car or motorcycle. FBG concentration was measured by the enzymatic reference method with hexokinase, using reagents of COBAS from Roche Diagnostics, Indianapolis, Indiana, USA. The serum concentration of TC and TG were determined by using an enzymatic colorimetric test with reagents of COBAS from Roche Diagnostics, all within 3 hours of collection.

\section{Variables}

Data on the intake of FV were collected with questions on the number of days a week vegetables or fruit were eaten, in addition to the number of servings on those days. Servings were defined with a pamphlet with pictures of examples of one serving. The number of servings per day of FV combined were calculated and recoded into the following variables: ' $\geq$ daily intake', ' $\geq 2$ servings daily' and ' $\geq 5$ servings daily', as well as 'number of servings/day'. As the numbers of participants reaching the recommended five servings per day was very low, the cut-off ' $\geq 2$ servings daily' was used in the analyses.

FBG $(\mathrm{mmol} / \mathrm{L})$, TG $(\mathrm{mmol} / \mathrm{L})$, TC $(\mathrm{mmol} / \mathrm{L})$ and BP $(\mathrm{mm} \mathrm{Hg})$ values were dichotomised according to established cut-offs for increased risk. ${ }^{10}$ For estimating $\mathrm{BP}$, the average of the two last of three measurements were used. BMI was calculated from the measured height and weight $\left(\mathrm{kg} / \mathrm{m}^{2}\right)$, and the ratio between waist and hip circumference was also calculated. Diabetes was defined as $\mathrm{FBG} \geq 7 \mathrm{mmol} / \mathrm{L}$ and/or self-reported diabetes, hypercholesterolaemia as TC $>5.17 \mathrm{mmol} / \mathrm{L}$, hypertriglyceridaemia as $\mathrm{TG} \geq 2 \mathrm{mmol} / \mathrm{L}$, hypertension as systolic $\mathrm{BP} \geq 140 \mathrm{~mm} \mathrm{Hg}$ and/or diastolic $\mathrm{BP} \geq 90$ and/ or self-reported current antihypertensive treatment for hypertension within 2 weeks prior to the interview, overweight and obesity as BMI $\geq 25 \mathrm{~kg} / \mathrm{m}^{2}$ and central obesity as WHR $>0.90$ in men and $>0.85$ in women. There were no missing data for BMI, WHR and BP, although 104 participants had missing values on lipid profile and 102 participants on FBG.

Educational level was assessed by asking for the highest level of completed education and recoded into 'primary' (completed primary school or less), 'secondary' (completed secondary school or high school) and 'higher' (completed college or university or a postgraduate). Income details were collected by asking for the average household earning per week, month or year. This was converted into US dollars (US\$) per day and recoded according to the World Bank cut-offs for moderate poverty (US $\$ 2 /$ day), '<US\$2/day' and ' $\geq$ US $\$ 2$ / day'. ${ }^{12}$ Smoking was recorded as currently smoking tobacco products, 'no' or 'yes'. Physical activity was estimated across all domains of work, household tasks, transportation and leisure-time activity. Low physical activity was defined as $<3$ days of vigorous-intensity activity for at least $20 \mathrm{~min} /$ week, or $<5$ days of moderate-intensity activity (with a minimum of at least 600 metabolic equivalent of task (MET)-min) per week, using standard METs based on the WHO guidelines. All participants gave information on their education, smoking and physical activity, and 91 had missing information (refused to answer) on income. Since income was a covariate in statistical analyses, those with missing information on income were excluded (total $\mathrm{n}=1395$, having completed STEPs 1 and 2).

\section{Statistical methods}

We explored associations between risk factors for chronic disease and a daily intake of at least two servings of FV using linear regressions. Risk factors (BMI, WHR, FBG, $\mathrm{BP}, \mathrm{TC}, \mathrm{TG})$ and intake of FV were included as outcome 
and exposure variables, respectively. We also described the relationships between our variables in a causal graph (directed acyclic graph (DAG) $)^{13}$ (figure 1). Based on the DAG, sex, age, location, education, income, smoking and low physical activity were possible confounders and were therefore adjusted for. BMI was included as a mediator in the analyses in which BMI was not the outcome, and was hence not adjusted for. To explore associations between diabetes, overweight, obesity, hypertension, hypertriglyceridaemia and hypercholesterolaemia and intake of FV, we used logistic regressions, with adjustments for the same potential confounders. We declared the complex sample design using 'svyset' command in STATA based on the different stages of sampling units of the study population using 2014 Myanmar census data.

We tested the assumptions of the linear model (linear effects and constant error variance) and the logistic model (linear effects) by plotting residuals versus predicted values. We looked for observations with a high influence by plotting $\delta$ - $\beta$ s versus the observation numbers and three outliers were removed for FBG. Possible interaction effects between the intake of $\mathrm{FV}$ and

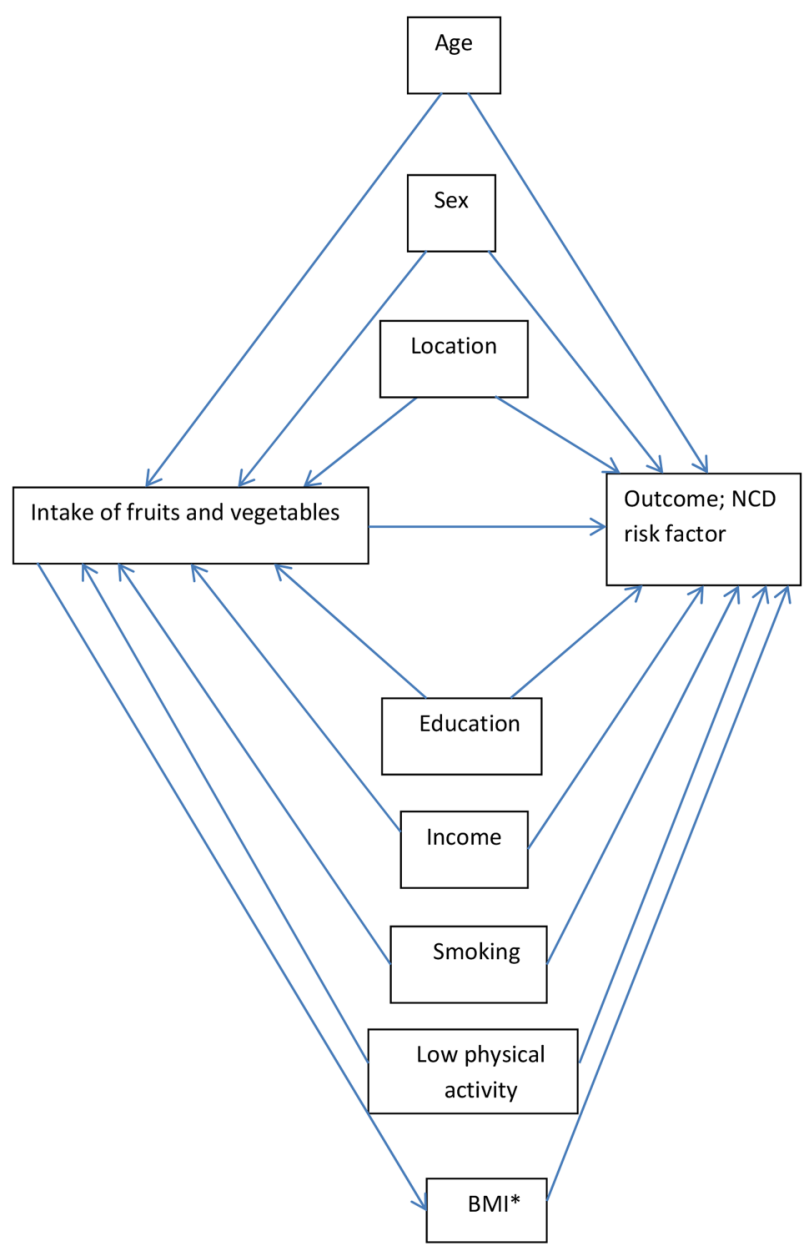

Figure 1 DAG of causal relationships. *BMI was included as a mediator in analyses with all outcomes, except when BMI was the outcome. BMI, body mass index; DAG, directed acyclic graph; NCD, non-communicable disease. sex, and between the intake of FV and location, were checked for. Interactions between sex and the intake of FV were found regarding cholesterol and hypercholesterolaemia. Results from these analyses were presented for men and women separately, and Stata V.14 (StataCorp 2015) was used for the analyses.

The paper was written as a part of a course in scientific writing in Myanmar (see online supplementary material).

\section{Ethics}

Written informed consent was obtained from the study participants; all information was handled with strict confidentially and the results of blood tests were provided to the participants. Participants with abnormal biological risk factors were advised to attend the closest health facility.

\section{RESULTS}

The mean age of the participants was 47 years (table 1 ). Of those living in urban areas, approximately half had an income of $\geq U S \$ 2 /$ day and one-third had a primary education only, whereas $21 \%$ had a college or university degree. In rural areas, almost two-thirds had an income of $<$ US $\$ 2 /$ day and three-fourths had a primary education only. Roughly one-fourth of the sample was tobacco smokers, and $11 \%$ had low levels of physical activity. The mean intake of fruits was 0.8 (SE 0.1) servings/day in urban areas and $0.6(0.0)$ servings/day in rural areas, while the mean intake of vegetables was 2.2 (SE 0.1) servings/day in urban areas and $1.2(0.1)$ servings/day in rural areas. Few participants reached the recommended five servings a day. The intake of FV varied with sociodemographic variables (table 2). It increased with education in urban and rural areas, and in rural areas it was highest among women.

On average, women eating at least two servings of $\mathrm{FV}$ per day had cholesterol levels $0.28 \mathrm{mmol} / \mathrm{L}$ lower than the levels of other women, adjusted for all included confounders (table 3). When adjusted for sex and age only, men eating at least two servings of FV per day had cholesterol levels $0.27 \mathrm{mmol} / \mathrm{L}$ higher than the levels of other men. In logistic regressions, adjusted for all included confounders, those eating at least two servings of fruits and vegetables daily had lower odds than others for hypertriglyceridaemia (0.72 (95\% CI 0.56 to 0.94$)$; table 4).

\section{DISCUSSION}

The intake of FV among adults in the Yangon region of Myanmar was low. A higher intake of FV was associated with lower odds of hypertriglyceridaemia, and among women lower levels of TC. Among men, a higher intake of FV was associated with higher levels of TC before adjustment for confounders other than age and sex.

The present study had a reasonable sample size and a high response rate, thereby strengthening the internal 
Table 1 Characteristics of the sample in STEP survey in the Yangon region of Myanmar, 2013-2014

\begin{tabular}{|c|c|c|c|c|}
\hline & Urban & Rural & p Value & Total \\
\hline Sex & & & NS & \\
\hline Men (\%) & 50.0 & 50.6 & & 50.3 \\
\hline Women (\%) & 50.0 & 49.4 & & 49.7 \\
\hline Age, mean (SE) & $48.2(0.8)$ & $46.3(0.8)$ & NS & $47.4(0.6)$ \\
\hline Education & & & 0.003 & \\
\hline Primary (\%) & 35.2 & 74.7 & & 51.5 \\
\hline Secondary or high school (\%) & 44.2 & 20.1 & & 34.3 \\
\hline College/university or postgraduate (\%) & 20.5 & 5.2 & & 14.2 \\
\hline Income & & & NS & \\
\hline$\geq$ US\$2/day (\%) & 47.7 & 34.9 & & 42.4 \\
\hline$<$ US\$2/day (\%) & 52.3 & 65.1 & & 57.6 \\
\hline Smoking tobacco (\%) & 26.5 & 31.9 & NS & 28.7 \\
\hline Low physical activity (\%) & 10.9 & 10.4 & NS & 10.7 \\
\hline Servings of fruits per day, mean (SE) & $0.8(0.1)$ & $0.6(0.0)$ & 0.006 & $0.7(0.0)$ \\
\hline Servings of vegetables per day, mean (SE) & $2.2(0.1)$ & $1.2(0.1)$ & $<0.001$ & $1.8(0.1)$ \\
\hline Fruits and vegetables & & & $<0.001$ & \\
\hline$\geq$ Daily (\%) & 88.7 & 76.7 & 0.008 & 83.8 \\
\hline$\geq 2$ servings daily (\%) & 65.9 & 30.3 & $<0.001$ & 51.3 \\
\hline$\geq 5$ servings daily (\%) & 22.8 & 6.0 & $<0.001$ & 16.1 \\
\hline
\end{tabular}

validity of the study. Non-attendance could have introduced a selection bias, but due to a response rate of $>90 \%$ in STEPs 1 and 2 and $>80 \%$ in STEP 3 , it is unlikely that it has had a high impact. ${ }^{14}$ People in the military, monks and nuns were not invited to participate the study. Owing to different life circumstances or a certain lifestyle, differences in their health compared with the rest of the population may lead to a selection bias. If so, the results are not possible to generalise to the entire Yangon population. Moreover, due to large demographic differences throughout Myanmar, the results may not be generalised to the country as a whole.

Questions about the intake of FV were rather simple, but answers could be subjected to recall bias or difficulties in reporting the correct days of eating these items, especially if consumption took place infrequently. Even though both surveys were carried out between September and November, some seasonal variations in the intake of FV may have occurred. Myanmar is an agricultural country, and fresh FV are available at a low cost throughout the season. Still, based on previous research, a low intake of FV was expected. ${ }^{5}$ The proportion of participants eating $\geq 5$ servings of FV daily declined since the last STEP survey in this region 10 years ago, from $30 \%$ to $16 \% .{ }^{15}$ The low intake was also comparable to other countries in the region. ${ }^{5}{ }^{16}$ Average vegetable consumption was at the level found in a larger survey in Thailand, where fruit consumption was lower. ${ }^{17}$ The study from Thailand reported higher intakes of FV among women, and with a higher education. ${ }^{17}$ In our

Table 2 Mean intake of fruit and vegetables (servings/day, mean (SE)) in various sociodemographic groups among participants in STEP survey in the Yangon region of Myanmar, 2013-2014; $N=1395$; sampling weights

\begin{tabular}{|c|c|c|c|c|c|c|}
\hline & $\begin{array}{l}\text { Fruit and } \\
\text { vegetable intake } \\
\text { Urban }\end{array}$ & $\begin{array}{l}\text { p Value } \\
\text { differences } \\
\text { Urban }\end{array}$ & $\begin{array}{l}\text { Fruit and } \\
\text { vegetable } \\
\text { intake Rural }\end{array}$ & $\begin{array}{l}\text { p Value } \\
\text { differences } \\
\text { Rural }\end{array}$ & $\begin{array}{l}\text { Fruit and } \\
\text { vegetable intake } \\
\text { Total }\end{array}$ & $\begin{array}{l}\text { p Value } \\
\text { difference } \\
\text { Total }\end{array}$ \\
\hline Income & & NS & & NS & & 0.014 \\
\hline$<$ US\$2/day & $2.8(0.2)$ & & $1.6(0.1)$ & & $2.3(0.1)$ & \\
\hline$\geq$ US\$2/day & $3.2(0.1)$ & & $1.9(0.1)$ & & $2.8(0.1)$ & \\
\hline Education & & 0.03 & & 0.05 & & 0.003 \\
\hline Primary & $2.8(0.1)$ & & $1.7(0.1)$ & & $2.1(0.1)$ & \\
\hline Secondary & $3.2(0.2)$ & & $2.0(0.1)$ & & $2.8(0.1)$ & \\
\hline Higher & $3.1(0.2)$ & & $2.1(0.2)$ & & $3.1(0.1)$ & \\
\hline Sex & & NS & & 0.04 & & NS \\
\hline Men & $3.1(0.2)$ & & $1.6(0.0)$ & & $2.5(0.1)$ & \\
\hline Women & $2.8(0.1)$ & & $2.0(0.1)$ & & $2.5(0.1)$ & \\
\hline
\end{tabular}

NS, not significant. 
Table 3 The effect of having $\geq 2$ servings of fruit and vegetables daily on various risk factors for NCD, compared with those with lower frequency of intake, among 25-74 years old in the Yangon region of Myanmar, taking part in STEP survey 20132014

\begin{tabular}{|c|c|c|c|}
\hline & $\begin{array}{l}\text { Crude } \\
\beta(95 \% \mathrm{Cl})\end{array}$ & $\begin{array}{l}\text { Adjusted for sex, age } \\
\beta(95 \% \mathrm{Cl})\end{array}$ & $\begin{array}{l}\text { Adjusted for sex, age, } \\
\text { location, education, } \\
\text { income, smoking and } \\
\text { low physical activity } \\
\beta(95 \% \mathrm{CI})\end{array}$ \\
\hline Body mass index & $0.74(-0.11$ to 1.60$)$ & $0.68(-0.02$ to 1.38$)$ & $0.23(-0.27$ to 0.73$)$ \\
\hline Waist hip ratio & $-0.00(-0.01$ to 0.01$)$ & $0.00(-0.01$ to 0.01$)$ & $-0.00(-0.01$ to 0.01$)$ \\
\hline Blood glucose & $0.03(-0.12$ to 0.18$)$ & $0.04(-0.11$ to 0.19$)$ & $-0.11(-0.29$ to 0.05$)$ \\
\hline Systolic blood pressure & $0.02(-2.43$ to 2.48$)$ & $0.24(-1.68$ to 2.16$)$ & $-0.04(-2.86$ to 2.77$)$ \\
\hline Diastolic blood pressure & $0.55(-0.31$ to 1.41$)$ & $0.59(-0.22$ to 2.16$)$ & $0.15(-1.11$ to 1.41$)$ \\
\hline Triglycerides & $-0.03(-0.17$ to 0.12$)$ & $-0.02(-0.16$ to 0.13$)$ & $-0.11(-0.23$ to 0.01$)$ \\
\hline Total cholesterol & $0.01(-0.21$ to 0.24$)$ & $\begin{array}{l}0.27(0.09 \text { to } 0.45) \text { men }^{*} \\
-0.23(-0.49 \text { to } 0.22) \text { women }\end{array}$ & $\begin{array}{l}0.15(-0.02 \text { to } 0.32) \text { men }^{*} \\
-0.28(-0.53 \text { to }-0.02) \text { women }\end{array}$ \\
\hline
\end{tabular}

study, a gender difference was only seen in rural areas, whereas an educational gradient was found in rural and urban areas. Increasing consumption with a higher income was seen in both studies. ${ }^{17} \mathrm{~A}$ higher intake of FV in higher socioeconomic groups has been reported in studies from low-income and high-income countries. ${ }^{18} 19$ In contrast to our study, several studies have found lower intakes of $\mathrm{FV}$ in urban than in rural areas in low-income countries. ${ }^{19} 20$

In studies from other countries in Asia, a higher intake of FV has been associated with an improved NCD risk profile, such as a lower systolic BP, waist circumference and low-density lipoprotein cholesterol in southern India ${ }^{6}$ and lower odds of obesity in Iran, ${ }^{21}$ as well as a reduced risk of CVD mortality in Japan. ${ }^{22}$ In China, a protective effect of high fruit consumption on coronary heart disease has been found among women, but not among men. ${ }^{23}$ In our study, the protective effect of a higher intake of FV is confirmed regarding hypertriglyceridaemia, and among women regarding cholesterol levels, though not regarding cholesterol levels among men. Differences between studies may have several explanations. The types of FV commonly eaten may vary between countries, and some FV have more protective benefits than others. ${ }^{24}{ }^{25}$ How FV are prepared influence their nutritional content, as raw and cooked vegetables may differ in content. $^{26}$ Fried vegetables are accompanied by fat, which may counteract any health benefits. ${ }^{27}$ Additionally, salt may be added and influence the association with BP. In Myanmar, many dishes are prepared with fish sauce, which contains quite a large amount of salt. Cooked or fried vegetables may also lose heat-sensitive or water-soluble vitamins. We did not ask about types of FV, or how they were prepared. Such

Table 4 The association (OR) between having $\geq 2$ servings of fruit and vegetables daily and various risk factors for NCD, compared with those with a lower frequency of intake among 25-74 years old in the Yangon region of Myanmar, taking part in the STEP survey 2013-2014

\begin{tabular}{|c|c|c|c|}
\hline & $\begin{array}{l}\text { Crude } \\
\text { OR }(95 \% \mathrm{Cl})\end{array}$ & $\begin{array}{l}\text { Adjusted for sex, age } \\
\text { OR }(95 \% \mathrm{CI})\end{array}$ & $\begin{array}{l}\text { Adjusted for sex, age, location, } \\
\text { education, income, smoking } \\
\text { and low physical activity } \\
\text { OR }(95 \% \mathrm{Cl})\end{array}$ \\
\hline Overweight & $1.20(0.70$ to 2.06$)$ & $1.18(0.71$ to 1.98$)$ & $0.90(0.62$ to 1.56$)$ \\
\hline Central obesity & $1.29(0.95$ to 1.74$)$ & $1.31(0.95$ to 1.79$)$ & $1.36(0.98$ to 1.89$)$ \\
\hline Diabetes & $1.28(0.95$ to 1.73$)$ & $1.30(0.95$ to 1.78$)$ & 1.35 (0.98 to 1.86$)$ \\
\hline Hypertension & 0.86 (0.68 to 1.09$)$ & $0.85(0.69$ to 1.06$)$ & $0.83(0.63$ to 1.11$)$ \\
\hline Hypertriglyceridaemia & $0.78(0.54$ to 1.11$)$ & $0.78(0.59$ to 1.11$)$ & $0.72(0.56$ to 0.94$)$ \\
\hline \multirow[t]{2}{*}{ Hypercholesterolaemia } & $0.98(0.52$ to 1.82$)$ & $1.76(0.86$ to 3.59$)$ men $^{*}$ & $1.41(0.72$ to 2.76$)$ men $^{*}$ \\
\hline & & 0.60 (0.29 to 1.12$)$ women & $0.52(0.26$ to 1.01$)$ women \\
\hline
\end{tabular}


questions should be included in future studies to inform the interpretation of the relationship between the intake of FV and NCD and its risk factors in this population.

Some of the associations between the intake of FV and NCD risk factors changed when adjusted for the potential confounders location, income, education, low physical activity and smoking. Previous analyses of our sample showed higher levels of BMI, systolic BP, FBG, TC and TG in urban than in rural areas (ASH, unpublished results). Confounding factors could work through lifestyle factors. Better off people may afford more of healthy and unhealthy foods, thus mitigating the positive effect of FV alone. A systematic review of socioeconomic differences in dietary patterns in low-income and middle-income countries reported that people in higher socioeconomic groups and in urban areas tended to eat more calories, protein, total fat, cholesterol, polyunsaturated and monounsaturated fatty acids, vitamins and fibre, as well as more $\mathrm{FV}^{20}$ Consequently, eating more $\mathrm{FV}$ may also be an indicator of higher intakes of more unhealthy foods. A higher intake of FV was associated with lower cholesterol levels among women, but higher levels among men. Other Asian studies have found a protective effect of FV among women, but not men. ${ }^{25} 28$ Gender differences in associations may be confounded by lifestyle-related variables differing between the sexes, or there could be biological differences. In our study, the intake of FV was slightly higher among women than in men in rural, though not in urban areas. Gender differences in amount and types of FV consumed could possibly influence associations between intake of $\mathrm{FV}$ and cholesterol levels. It could also be that men eating more FV have a different eating pattern from women eating more FV, including more unhealthy foods.

\section{Implications}

The intake of fruits and vegetables among adults in the Yangon region, Myanmar was far below recommended levels, with socioeconomic differences. According to previous research, a low intake of fruits and vegetables should be an important risk factor for NCD. With the exception of cholesterol level among men, this was confirmed in the present study. People eating more fruits and vegetables had lower odds of hypertriglyceridemia, and among women, more favorable cholesterol levels. Unmeasured aspects of diet may explain the positive association with cholesterol levels among men. Future studies including more detailed information, such as types of fruits and vegetables, more food items and ways of preparation, is warranted to provide a better picture of the association between dietary habits and risk of NCD in the Yangon region, Myanmar.

\section{CONCLUSION}

A high intake of $\mathrm{FV}$ was associated with a lower prevalence of hypertriglyceridaemia. It was also associated with levels of TC, negatively among women, and positively among men.

\section{Author affiliations}

${ }^{1}$ Institute of Health and Society, University of Oslo, Oslo, Norway

${ }^{2}$ University of Pharmacy, Yangon, Myanmar

${ }^{3}$ University of Medicine-Mandalay, Mandalay, Myanmar

${ }^{4}$ University of Medical Technology, Yangon, Myanmar

${ }^{5}$ Directorate of Medical Services, Napidaw, Myanmar

${ }^{6}$ University of Nursing, Yangon, Myanmar

${ }^{7}$ University of Medicine 2, Yangon, Myanmar

${ }^{8}$ University of Nursing, Mandalay, Myanmar

${ }^{9}$ University of Medicine 1, Yangon, Myanmar

${ }^{10}$ University of Public Health, Yangon, Myanmar

${ }^{11}$ University of Pharmacy, Mandalay, Myanmar

${ }^{12}$ University of Dental Medicine, Yangon, Myanmar

${ }^{13}$ Military Institute of Nursing and Paramedical Sciences, Napidaw, Myanmar

${ }^{14}$ Food and Drug Administration, Napidaw, Myanmar

${ }^{15}$ University of Medical Technology, Mandalay, Myanmar

${ }^{16}$ Department of Medical Care, Ministry of Health, Napidaw, Myanmar

Contributors EB and MK conceived the idea and design for the article. MK drafted the article. All the authors contributed to the identification of the final objectives, conducted the statistical analyses, the interpretation of data, the reporting of results and in the final stage of writing.

Funding This work was supported by the Norwegian Agency for Development Cooperation (Norad), project MY-NORTH 1300650, MMR-13/0049 NORHED Espen.

Competing interests None declared.

Ethics approval Norwegian Regional Committees for Medical and Health Research Ethics (2013/1088) and Department of Health, Myanmar.

Provenance and peer review Not commissioned; externally peer reviewed.

Data sharing statement No additional data are available.

Open Access This is an Open Access article distributed in accordance with the Creative Commons Attribution Non Commercial (CC BY-NC 4.0) license, which permits others to distribute, remix, adapt, build upon this work noncommercially, and license their derivative works on different terms, provided the original work is properly cited and the use is non-commercial. See: http:// creativecommons.org/licenses/by-nc/4.0/

\section{REFERENCES}

1. Lim SS, Vos T, Flaxman AD, et al. A comparative risk assessment of burden of disease and injury attributable to 67 risk factors and risk factor clusters in 21 regions, 1990-2010: a systematic analysis for the Global Burden of Disease Study 2010. Lancet 2012;380:2224-60.

2. Van Duyn MA, Pivonka E. Overview of the health benefits of fruit and vegetable consumption for the dietetics professional: selected literature. J Am Diet Assoc 2000;100:1511-21.

3. World Health Organisation/Food and Agriculture organization. Diet, nutrition, and the prevention of chronic diseases: report of a joint WHO/FAO expert consultation. Geneva, 2003.

4. Pomerleau J, Lock K, McKee M, et al. The challenge of measuring global fruit and vegetable intake. J Nutr 2004;134:1175-80.

5. Hall JN, Moore S, Harper SB, et al. Global variability in fruit and vegetable consumption. Am J Prev Med 2009;36:402-9.

6. Radhika G, Sudha V, Mohan SR, et al. Association of fruit and vegetable intake with cardiovascular risk factors in urban south Indians. Br J Nutr 2008;99:398-405.

7. Djoussé $\mathrm{L}$, Arnett $\mathrm{DK}$, Coon $\mathrm{H}$, et al. Fruit and vegetable consumption and LDL cholesterol: the National Heart, Lung, and Blood Institute Family Heart Study. Am J Clin Nutr 2004;79:213-17.

8. Dauchet L, Dallongeville J. Fruit and vegetables and cardiovascular disease: epidemiological evidence from the non-Western world. $\mathrm{Br}$ J Nutr 2008;99:219-20.

9. World Health Organization. Cause-specific mortality. WHO regions. Estimates for 2000-2012. World Health Organization. http://www. who.int/healthinfo/global_burden_disease/estimates/en/index1.html (accessed 12 Oct 2015). 
10. World Health Organization. STEP manual. The WHO STEPwise approach to chronic disease risk factor surveillance. Geneva, Switzerland, 2008.

11. World Health Organization. Noncommunicable Disease Risk Factor Survey Myanmar 2009. India, 2011.

12. World Bank. Poverty Analyses. http://web.worldbank.org/WBSITE/ EXTERNALTOPICS/EXTPOVERTY/EXTPA/0,menuPK:430373 pagePK:149018 piPK:149093 theSitePK:430367,00.html (accessed 23 Jun 2015).

13. Veierød MB, Lydersen S, Laake P. Medical statistics in clinical and epidemiological research. Oslo: Gyldendal Akademisk, 2012.

14. Søgaard AJ, Selmer R, Bjertness E, et al. The Oslo Health Study: the impact of self-selection in a large, population-based survey. Int $J$ Equity Health 2004;3:3.

15. Ko-Ko-Zaw, Tint-Swe-Latt, Phyu-Phyu-Aung, et al. Prevalence of hypertension and its associated factors in the adult population in Yangon Division, Myanmar. Asia Pac J Public Health 2011;23:496-506.

16. Kanungsukkasem $\mathrm{U}, \mathrm{Ng} \mathrm{N}$, Van Minh $\mathrm{H}$, et al. Fruit and vegetable consumption in rural adults population in INDEPTH HDSS sites in Asia. Glob Health Action 2009;2.

17. Satheannoppakao W, Aekplakorn W, Pradipasen M. Fruit and vegetable consumption and its recommended intake associated with sociodemographic factors: Thailand National Health Examination Survey III. Public Health Nutr 2009;12:2192-8.

18. Giskes K, Avendano M, Brug J, et al. A systematic review of studies on socioeconomic inequalities in dietary intakes associated with weight gain and overweight/obesity conducted among European adults. Obes Rev 2010;11:413-29.
19. Bhagyalaxmi A, Atul T, Shikha J. Prevalence of risk factors of non-communicable diseases in a District of Gujarat, India. $J$ Health Popul Nutr 2013;31:78-85.

20. Mayén AL, Marques-Vidal P, Paccaud F, et al. Socioeconomic determinants of dietary patterns in low- and middle-income countries: a systematic review. Am J Clin Nutr 2014;100:1520-31.

21. Dastgiri S, Mahdavi R, TuTunchi H. Prevalence of obesity, food choices and socio-economic status: a cross-sectional study in the north-west of Iran. Public Health Nutr 2006;9:996-1000.

22. Okuda N, Miura K, Okayama A, et al. Fruit and vegetable intake and mortality from cardiovascular disease in Japan: a 24-year follow-up of the NIPPON DATA80 Study. Eur J Clin Nutr 2015;69:482-8.

23. Yu D, Zhang X, Gao YT, et al. Fruit and vegetable intake and risk of CHD: results from prospective cohort studies of Chinese adults in Shanghai. Br J Nutr 2014;111:353-62.

24. Hung $\mathrm{HC}$, Joshipura $\mathrm{KJ}$, Jiang $\mathrm{R}$, et al. Fruit and vegetable intake and risk of major chronic disease. J Natl Cancer Inst 2004;96:1577-84.

25. Oude Griep LM, Verschuren WM, Kromhout D, et al. Colours of fruit and vegetables and 10-year incidence of CHD. Br J Nutr 2011;106:1562-9.

26. Oude Griep LM, Geleijnse JM, Kromhout D, et al. Raw and processed fruit and vegetable consumption and 10-year coronary heart disease incidence in a population-based cohort study in the Netherlands. PLOS ONE 2010;5:e13609.

27. Shi Z, Hu X, Yuan B, et al. Vegetable-rich food pattern is related to obesity in China. Int J Obes (Lond) 2008;32:975-84.

28. Nakamura K, Nagata C, Oba S, et al. Fruit and vegetable intake and mortality from cardiovascular disease are inversely associated in Japanese women but not in men. J Nutr 2008;138:1129-34. 